\title{
Barriers to Receiving Tissue Plasminogen Activator in Patients with Ischemic Stroke
}

\author{
Monirsadat Mirzadeh $^{1}$ (D), Hossein Mozhdehipanah ${ }^{2}$ (D), Ali Emami ${ }^{3}$ (D, Niloofar Motamed M.5* $^{*}$ \\ 1. Metabolic Diseases Research Center, Research Institute for Prevention of Non-Communicable Diseases, Qazvin University of Medical Sciences, Qazvin, Iran \\ 2. Department of Neurology, Bou-Ali Sina Hospital, Qazvin University of Medical Sciences, Qazvin, Iran. \\ 3. Student Research Committee, Qazvin University of Medical Sciences, Qazvin, Iran. \\ 4. Persian Gulf Nuclear Medicine Research Center, The Persian Gulf Biomedical Research Center, Bushehr University of Medical Sciences, Bushehr, Iran. \\ 5. Department of Community Medicine, School of Medicine, Bushehr University of Medical Sciences, Bushehr, Iran.
}

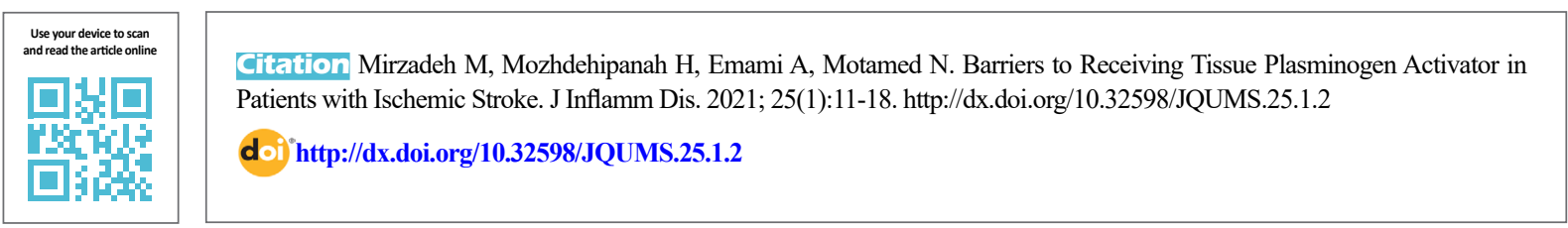

\section{(i) (5)}

Article info:

Received: 29 Mar 2020

Accepted: 31 Oct 2020

Publish: 01 Apr 2021
Keywords:

Stroke, Time, Health services accessibility, Therapeutics

\section{ABSTRACT}

Background: Cerebrovascular diseases are the second common cause of mortality worldwide. The onset of reperfusion in the first 3-4.5 hours is a predictive factor of treatment.

Objective: The present study investigated barriers to receiving tissue plasminogen activator in patients with ischemic stroke.

Methods: This cross-sectional study examined 191 patients with first-ever stroke referring to the emergency department of the Persian Gulf Martyrs Hospital of Bushehr City, Iran, in 2016. One checklist was completed which included demographic data, history of diseases, knowledge of stroke symptoms, and intervals regarding the onset of symptoms to informing emergency, informing emergency on arrival at the emergency department of the hospital, and making the diagnosis for the patients. The obtained data were analyzed in SPSS v. 19.

Results: Mean \pm SD age of the patients was $65.92 \pm 12.48$ years. The majority of patients under investigation (55.5\%) were female, $63.4 \%$ were married, $56 \%$ were illiterate and $72.3 \%$ resided in other districts of Bushehr province. Mean duration between onset of symptoms and arrival at emergency department, onset of symptoms and call the emergency service, time of arrival at emergency department to perform brain Computer Tomography (CT) scan and also to be counseled by a neurologist were $699.66,195.51,45.11$ and 423.62 minutes, respectively. Finally 14.6 percent of patients were qualified to be treated with tPA.

Conclusion: The main barrier to timely therapy is a delay in golden time. Therefore, public education to promote public awareness could be of great benefit in reducing the referral delay time.

\footnotetext{
* Corresponding Author:

Niloofar Motamed

Address: Department of Community Medicine, School of Medicine, Bushehr University of Medical Sciences, Bushehr, Iran.

Phone: +98 (917) 3204322

E-mail: motamed.drn@gmail.com
} 


\section{Introduction}

troke is caused by the interruption of blood flow to the brain (ischemic) or bleeding intracranial (hemorrhagic). According to the World Health Organization, stroke is introduced as symptoms of rapid progression of localized or diffuse brain dysfunction under 24 hours. Approximately $80 \%$ of stroke cases are ischemic [1]. The spread of disability and mortality due to stroke has become among the health concerns. It was estimated that globally, 15 million individuals encounter stroke, annually [2].

Cerebrovascular diseases are the second most common cause of death and the sixth leading cause of the burden of disease worldwide; they are expected to reach fourth place by $2020[3,4]$. More than $80 \%$ of all stroke deaths occur in developing countries [3].

Hypertension, hyperlipidemia, a history of the previous stroke, smoking, and diabetes are the main risk factors for stroke. The symptoms of stroke depend on the affected part of the brain. The major symptoms are the paralysis of the limbs, ataxia, aphasia, vision disturbance, and paresthesia in the body [5].

Fasting Blood Sugar (FBS), lipid profile, Complete Blood Count (CBC), Electrocardiogram (ECG), and Computer Tomography (CT) scan should be ordered in all stroke patients [6]. A brain CT scan is required in every patient with a stroke. In the first 12 hours, the stroke may not be visible in the CT scan. It is recommended that more accurate imaging procedures, such as Magnetic Resonance Imaging (MRI), angiography, and invasive catheter angiography be performed only in specific patients [7]

The most common treatment recommended by the American Heart Association/American Stroke Association (AHA/ASA) in the ischemic type; involves the intravenous administration of Tissue Plasminogen Activator (tPA). Despite the effect of tPA on improving neurological outcomes, most patients with ischemic stroke are not treated with tPA. This is because patients are referred for treatment after the allotted time (3-4.5 hours) [8].

According to a Canadian study, $60 \%$ of patients with ischemic stroke did not return for antithrombotic therapy at the right time; $30 \%$ were not transformed by ambulance; only $22 \%$ within one hour of receiving to hospital underwent brain CT, and just of $8 \%$ of patients with ischemic stroke received tPA [9].
A study reported that 4 out of 5 Americans drive to a stroke central hospital about an hour; however, only $4 \%$ of them received tPA. The reperfusion of blood flow within 3-4.5 hours is a predictive factor of effective treatment [10].

The most common barrier to receiving tPA on time is the loss of treatment window time due to the delayed arrival at the referral center (39\%). Other barriers include the reluctance and procrastination of physicians (19\%) and the lack of coordination between emergency medical technicians and the neurology center team (14\%). The lack of qualified and experienced nurses to provide care to stroke patients in $3 \%$ of the referral centers was identified as another barrier. The lack of emergency medical technicians was reported as another obstacle in $6 \%$ of centers. The managers of the referral center noted that physicians wait until the end of the window period of treatment, expecting the improvement of the patient's symptoms before administering tPA [11]. This study investigated barriers to receiving tPA in patients with ischemic stroke.

\section{Materials and Methods}

The statistical population of the present cross-sectional study was all patients referring to Bushehr Persian Gulf Martyrs Hospital for the first time in Bushehr City, Iran, in 2016 with symptoms of a stroke. The inclusion criteria were ischemic and hemorrhagic stroke according to the diagnosis of a neurologist consulting the project, stroke for the first time, and living in Bushehr Province, Iran. The exclusion criteria were receiving initial ischemic treatment in the other provinces, the onset of early symptoms of stroke during sleep, and a history of paresthesia in the face, paresis, and aphasia which indicate a previous stroke.

The applied data collection form included demographic data (age, gender, educational level, marital status, \& the place of residence); questions about time intervals (from the onset of symptoms until calling the emergency service; referring to the emergency medical technician and referring until admission to the emergency room of a hospital; time interval from emergency room admission until first visiting by the emergency physician; visiting a neurologist; preparing tests; performing brain CT scan; the interpretation of brain CT scan by a neurologist, \& the time of starting stroke treatments); risk factors for receiving anticoagulants, the knowledge of stroke symptoms in patients; the type of stroke; the time of treatment for all cases of stroke, and the contraindications of starting tPA. Finally, for all patients who called the emergency service after starting the onset of symptoms, the times were checked with the emergency medical technicians, 
and the exact time was noted. The necessary information was collected by a neurologist when the patients were hospitalized.

The collected data were analyzed in SPSS v. 19, using the Chi-squared test, Mann-Whitney U test, and Kruskal-Wallis test to examine the relationship between the studied times and, the qualitative variables of two and more states. Quantitative variables were measured using descriptive statistics (frequency, relative frequency, mean, \& standard deviation) and the KolmogorovSmirnov test (to determine the normal distribution). The significant difference was considered at $\mathrm{P}<0.05$.

\section{Results}

The Mean \pm SD age of the examined patients was $65.92 \pm 12.48$ years, ranging from 34 to 90 years. The majority $(55.5 \%)$ of the study subjects were female, $63.4 \%$ (121s) were married, and 56\% (107) of study participants were illiterate. Moreover, 138(72.3\%) individuals lived in the cities of Bushehr Province (Table1).

Unilateral paresthesia (67\%) and unilateral paresis $(48.2 \%)$ were the most frequent primary symptoms of the study patients. Furthermore, $79.6 \%$ of the examined patients presented progressing symptoms and $91.6 \%$ (175) had companions at the time of stroke. Most of the explored patients (79.6\%) and their companions (69.1\%) were unaware of the symptoms of a stroke.

Ninety-Two Percent of strokes were ischemic and 7.3\% were hemorrhagic. Among ischemic strokes, 72 (40.7\%) cases had a contraindication to injection tPA. Besides, 61(31.9\%) patients had hypertension (systolic: $>185$ $\mathrm{mmHg}$, diastolic: $>110 \mathrm{mmHg}$ ) at the time of admission to the hospital emergency room. More than half (113) of the explored patients reported a history of hypertension. The history of diabetes and cardiovascular disease was also collected ( $33.5 \%$ \& $28.3 \%$, respectively).

The Mean \pm SD time interval between the onset of symptoms and referral to the hospital was $699.66 \pm 881.68$ minutes. No significant relationship was found between the times divided in Table 2 and gender, age, urban and rural area of living, educational level, and marital status $(\mathrm{P}>0.05)$. There was no significant relationship between gender, educational level, marital status, age, and place of residence, and the awareness of stroke symptoms $(\mathrm{P}>0.05)$. There was a significant relationship between the place of residence and calling the emergency service $(\mathrm{P}=0.013)$. Finally, $14.6 \%$ of the explored patients were eligible for receiving tPA.

\section{Discussion}

This study investigated the barriers to receiving tPA in patients with ischemic stroke referring to the Bushehr Persian Gulf Martyrs Hospital in 2016. The relevant results revealed that $35.1 \%$ of the examined patients in $<3$ hours were referred to the hospital and $20.4 \%$ of the explored patients were aware of the symptoms of a stroke.

In this study, the mean age of the patients with acute stroke was 65.9 years which was in line with those obtained by Hatamabadi et al. (59.7 years) and Daneshfard et al. (68.33 years) $[12,13]$. The relevant mean age in other developing countries is about 65 years. However, it seems to be higher in developed countries [14]; this issue indicates that in this study, stroke occurs to younger ages.

Most of the examined patients were women (55.5\%), i.e., consistent with the study of Hatamabadi et al.where $51.8 \%$ of stroke cases were reported in women [12]. In the study of Suwanwela et al. the onset of stroke was higher in men in all age groups [14]. The data of this study were not obtained from data registers and numerous patients were excluded from the study; therefore, it is impossible to speak with certainty about this. Additionally, this study was performed on CVA (Cerebrovascular accident) patients for the first time, and this difference can be justified.

In this study, $51.9 \%$ of women were married, i.e., similar to the results of Ostovar et al. in the cohort study on the elderly in Bushehr Province (57.2\%) [15].

Fifty-Six Percent of the explored patients were illiterate and women had a higher rate $(65 \%)$. In another study, $51.8 \%$ of the patients were illiterate. It seems that individuals with lower levels of education are more prone to have a stroke [16].

In the present study, the most common early symptoms of stroke were hemiparesis $(67 \%)$ and hemiplegia (48.2\%). Similar results were obtained by Tallawy and associates [16]. As per Daneshfard et al., hemiparesis and dysarthria were the most common early symptoms [13].

In the present study, hypertension (59.2\%), diabetes $(33.5 \%)$, and ischemic heart disease $(28.3 \%)$ were the most frequent comorbidities in the examined patients with stroke, i.e., consist to the results of Daneshfard et al.'s study [13]. In a study on stroke in Mashhad, the most common underlying disease was hypertension [17]. Furthermore, in the study of Ayromlou et al., hy- 
Table 1. Demographic characteristics of the study participants

\begin{tabular}{|c|c|c|}
\hline \multicolumn{2}{|c|}{ Variables } & No.(\%) \\
\hline \multirow{3}{*}{ Gender } & Male & $106(55.5)$ \\
\hline & & \\
\hline & Female & $85(44.5)$ \\
\hline \multirow{5}{*}{ Marital status } & Single & $9(4.7)$ \\
\hline & Married & $121(63.4)$ \\
\hline & & \\
\hline & Widowed & $60(31.4)$ \\
\hline & Divorced & $1(0.5)$ \\
\hline \multirow{7}{*}{ Educational level } & Illiterate & $107(56)$ \\
\hline & $\begin{array}{c}\text { To extent of reading and writ- } \\
\text { ing }\end{array}$ & $53(27.7)$ \\
\hline & Under diploma & $9(4.7)$ \\
\hline & & \\
\hline & Diploma & $15(7.9)$ \\
\hline & Associate degree & $4(2.1)$ \\
\hline & BA and higher & $3(1.6)$ \\
\hline \multirow{2}{*}{ Place of residence } & Urban & $138(72.3)$ \\
\hline & Rural & $53(27.7)$ \\
\hline
\end{tabular}

pertension $(66.5 \%)$ and diabetes $(17.7 \%)$ were the most common comorbidities [18].

About $80 \%$ of patients and $70 \%$ of their companions reported no knowledge of the symptoms of a stroke. Aboutalebi et al. reported the average knowledge of individuals (aged $>25$-year-olds) as high [19].

The Mean \pm SD time of the onset of symptoms by referring to the emergency department was $669.66 \pm 881.688$ minutes, i.e., less than that of the study of Hatamabadi et al. that equaled $1918 \pm 1204$ minutes [12]. This reduction in time may be because, in the present study, all diagnostic and therapeutic measures were performed in one hospital; thus, the time from the onset of symptoms to hospitalization, diagnosis, and therapeutic measures in other hospitals were not wasted. However, approximately $35.1 \%$ of the explored patients referred within 3 hours of the onset of symptoms, i.e., consistent with the study of Mojdehipanah et al. (67\% of the patients referred after the first 3 hours of the onset of symptoms). In the study of Ayromlou et al., 31.3\% of the patients were referred in the first 3 hours $[18,20]$.

In the present study, the Mean $\pm \mathrm{SD}$ time of admitting to the emergency room to performing laboratory tests was
$190.718 \pm 264.5$ minutes, i.e., very high, compared to the appropriate time mentioned by ASA/AHA, i.e., 45 minutes [21].

The mean time for admitting to the emergency room until performing a CT scan was 45.11 minutes, i.e., 25 minutes longer than the appropriate time set by the ASA/ AHA for a CT scan [21]; therefore, this service is inappropriate for the patients. However, in comparison with the study of Ayromlou et al. who reported 91 minutes, and Hatamabadi et al. who documented 89 minutes for the same value, the time was more appropriate in this research $[12,18]$. This issue highlights the coordination between the radiology and emergency departments. In the present study, the Mean \pm SD time to refer to the emergency room until receiving a physical examination by the neurologist was measured as $423.62406 .147 \mathrm{~min}$ utes, i.e., much higher than that obtained by Hatamabadi

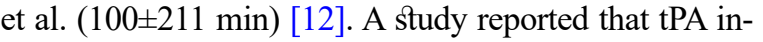
jection at the imaging center immediately after performing CT scan decreased 26 minutes from the time of the main protocol (when the patient returns to the emergency room, then was injected) [22].

Mojdehipanah et al. considered the delay of visiting by the neurologist as the most main in the failure of the tPA 
Table 2. The frequency of the time interval

\begin{tabular}{|c|c|c|c|c|c|}
\hline Time Interval (Minute) & No.* & Mean $\pm S D$ & Median & Max. & Min. \\
\hline $\begin{array}{c}\text { The onset of the symptoms until deciding to go } \\
\text { to the hospital }\end{array}$ & 191 & $699.6 \pm 881.6$ & 400 & 4320 & 30 \\
\hline $\begin{array}{l}\text { The onset of symptoms until calling the emer- } \\
\text { gency service }\end{array}$ & 39 & $195.5 \pm 322.1$ & 20 & 1200 & 5 \\
\hline $\begin{array}{l}\text { Calling the emergency service until visiting by the } \\
\text { emergency medical technician }\end{array}$ & 39 & $7.0 \pm 4.696$ & 5 & 30 & 3 \\
\hline $\begin{array}{l}\text { Visiting by the emergency medical technician } \\
\text { until referring to the hospital }\end{array}$ & 38 & $20.89 \pm 6.821$ & 20 & 37 & 9 \\
\hline $\begin{array}{c}\text { Admitting in emergency room until visiting by } \\
\text { neurologist }\end{array}$ & 186 & $432.6 \pm 406.1$ & 305 & 2550 & 5 \\
\hline $\begin{array}{l}\text { Admitting in emergency room until performing } \\
\text { laboratory tests }\end{array}$ & 172 & $190.7 \pm 297.65$ & 264.5 & 1440 & 32 \\
\hline $\begin{array}{c}\text { Admitting in emergency room until performing } \\
\text { brain CT scan }\end{array}$ & 186 & $45.11 \pm 45.658$ & 30 & 335 & 10 \\
\hline Admitting in emergency room until starting tPA & 181 & $176.9 \pm 275.2$ & 90 & 2550 & 15 \\
\hline
\end{tabular}

position [20]. Delayed visits by the neurologist and the absence of the neurologist resident in that center can justify this difference with the present study. Treatment in this center is performed by an emergency physician. Hargis et al. reported the experience of neurologists and teaching centers with residents accelerated tPA injection [11].

The mean time for admitting to the emergency room until starting the treatment was 176.96 minutes, i.e., similar to $164 \pm 320$ minutes in the study of Hatamabadi and colleagues [12]. However, this rate is very different, compared to the appropriate time in ASA/AHA (i.e., one hour) [21]. According to Ayromlou et al., the time of starting the treatment was 147 minutes [18]. The results reveal that in Bushehr City, the time of starting the treatment is longer, despite the shorter diagnosis time (with brain CT scan) that requires more coordination in the emergency department.

The average time of calling emergency service until visiting by emergency medical technicians, is 7 minutes, i.e., less than the standard time ( 8 minutes) for responding to the emergency missions. A reason for the delay in performing the emergency missions is the crowded routes. Bushehr City has no significant traffic; thus, the mentioned 7 minutes is reasonable.

Given that time plays a critical role in strokes, based on the present study data, the time of the onset of the symptoms until initiating the treatment (the onset of the symptoms until referring to the hospitals, admitting to the emergency room until visiting by the neurologist, performing laboratory tests, performing brain CT scan until starting treatment) is higher, compared to the standard service time recommended by the AHA/ASA. Thus, patients lose the golden time and further complications have remained. As mentioned in the discussion, delayed referring after the onset of symptoms was among the main causes of the loss of the golden time (about 70\%), i.e., associated with the low awareness of stroke symptoms in patients and their companions. It is suggested that by using the information provided by the physicians and public media, such as magazines and television, we increase individuals' awareness about stroke and its common symptoms. Proper teaching of the general practitioner who is working in the healthcare centers as the first referral place for stroke is also helpful. These issues require comprehensive cooperation between the physicians, healthcare centers, and the media.

\section{Conclusion}

The main barrier to timely therapy is a delay in golden time. Therefore, public education to promote public awareness could be of great benefit in reducing the referral delay time. Delay in the preparation of laboratory tests and performing brain CT scans are crucial reasons in providing services to patients; thus, it is recommended for the patients who could benefit from receiving tPA, the necessary coordination between the laboratories and imaging centers of the hospital be urgently conducted.

Due to the significance of time in managing patients with acute stroke to receive treatment, it is recommended that these patients be immediately referred to an emergency physician to be visited by the emergency physicians in the shortest possible time. 


\section{Ethical Considerations}

\section{Compliance with ethical guidelines}

This study was approved by the Research Ethics Committee of Bushehr Faculty of Medical Sciences.

Funding

This study was extracted from a MA. thesis of first author approved by the Bushehr Faculty of Medical Sciences, Bushehr.

\section{Authors' contributions}

Conceptualization: Niloofar Motamed and Hossein Mozhdehipanah; Writing - original draft and Data analysis: Monirsadat Mirzadeh and Ali Emami; Writing - review \& editing, supervision, and project administration: Niloofar Motamed.

\section{Conflict of interest}

The authors declare no conflicts of interest.

\section{Acknowledgments}

The authors would like to thank the Clinical Research Development Center of Persian Gulf Martyrs Hospital and the research committee of Qazvin and Bushehr Universities of Medical Sciences.

\section{References}

[1] Felling RJ, Sun LR, Maxwell EC, Goldenberg N, Bernard T. Pediatric arterial ischemic stroke: Epidemiology, risk factors, and management. Blood Cells Mol Dis. 2017; 67:23-33. [DOI:10.1016/j.bcmd.2017.03.003] [PMID]

[2] Guzik A, Bushnell Ch. Stroke epidemiology and risk factor management. Continuum. 2017; 23((1, Cerebrovascular Disease):15-39. [DOI:10.1212/CON.0000000000000416] [PMID]

[3] Venketasubramanian N, Yoon BW, Pandian J, Navarro JC. Stroke epidemiology in South, East, and South-East Asia: A review. J Stroke. 2017; 19(3):286-94. [DOI:10.5853/ jos.2017.00234] [PMID] [PMCID]

[4] Aked J, Delavaran H, Norrving B, Lindgren A. Temporal trends of stroke epidemiology in Southern Sweden: A population-based study on stroke incidence and early case-fatality. Neuroepidemiology. 2018; 50(3-4):174-82. [DOI:10.1159/000487948] [PMID]
[5] Favate AS, Younger DS. Epidemiology of ischemic stroke. Neurol Clin. 2016; 34(4):967-80. [DOI:10.1016/j. ncl.2016.06.013] [PMID]

[6] Hasan TF, Rabinstein AA, Middlebrooks EH, Haranhalli N, Silliman SL, Meschia JF, et al., editors. Diagnosis and management of acute ischemic stroke. Mayo Clin Proc. 2018 93(4):523-38. [DOI:10.1016/j.mayocp.2018.02.013] [PMID]

[7] Arch AE, Weisman DC, Coca S, Nystrom KV, Wira III CR, Schindler JL. Missed ischemic stroke diagnosis in the emergency department by emergency medicine and neurology services. Stroke. 2016; 47(3):668-73. [DOI:10.1161/STROKEAHA.115.010613] [PMID]

[8] Matys T, Pawlak R, Matys E, Pavlides C, McEwen BS, Strickland S. Tissue plasminogen activator promotes the effects of corticotropin-releasing factor on the amygdala and anxietylike behavior. Proc Natl Acad Sci U S A. 2004; 101(46):16345-50. [DOI:10.1073/pnas.0407355101] [PMID] [PMCID]

[9] O'Brien EC, Xian Y, Xu H, Wu J, Saver JL, Smith EE, et al. Hospital variation in home-time after acute ischemic stroke: Insights from the PROSPER study (Patient-Centered Research into Outcomes Stroke Patients Prefer and Effectiveness Research). Stroke. 2016; 47(10):2627-33. [DOI:10.1161/ STROKEAHA.116.013563] [PMID]

[10] Alawieh A, Pierce AK, Vargas J, Turk AS, Turner RD, Chaudry MI, et al. The golden 35 min of stroke intervention with ADAPT: Effect of thrombectomy procedural time in acute ischemic stroke on outcome. J Neurointerv Surg. 2018 10(3):213-20. [DOI:10.1136/neurintsurg-2017-013040] [PMID]

[11] Hargis M, Shah JN, Mazabob J, Rao CV, Suarez JI, Bershad EM. Barriers to administering intravenous tissue Plasminogen Activator (tPA) for acute ischemic stroke in the emergency department: A cross-sectional survey of stroke centers. Clin Neurol Neurosurg. 2015; 135:79-84. [DOI:10.1016/j. clineuro.2015.04.027] [PMID]

[12] Hatamabadi HR, Mansourifar H, Asarzadegan F, Shojaee $\mathrm{M}$. Barriers to on time delivery of thrombolytic therapy for patients with acute stroke. J Mazandaran Univ Med Sci. 2013; 23(102):107-10. [In Persian] http://jmums.mazums.ac.ir/ article-1-2397-en.html

[13] Daneshfard B, Izadi S, Shariat A, Toudaji MA, Beyzavi Z, Niknam L. Epidemiology of stroke in Shiraz, Iran. Iran J Neurol. 2015; 14(3):158-63. [PMID] [PMCID]

[14] Suwanwela NC, Poungvarin N, Asian Stroke Advisory Panel. Stroke burden and stroke care system in Asia. Neurol India. 2016; 64(7):46-51. [DOI:10.4103/0028-3886.178042] [PMID]

[15] Ostovar A, Nabipour I, Larijani B, Heshmat R, Darabi H, Vahdat $\mathrm{K}$, et al. Bushehr Elderly Health (BEH) Programme, phase I (cardiovascular system). BMJ Open. 2015; 5(12):e009597. [DOI:10.1136/bmjopen-2015-009597] [PMID] [PMCID]

[16] El Tallawy HN, Farghaly WM, Badry R, Hamdy NA, Shehata GA, Rageh TA, et al. Epidemiology and clinical presentation of stroke in Upper Egypt (desert area). Neuropsychiatr Dis Treat. 2015; 11:2177-83. [DOI:10.2147/NDT.S87381] [PMID] [PMCID]

[17] Azarpazhooh MR, Etemadi MM, Donnan GA, Mokhber N, Majdi MR, Ghayour-Mobarhan M, et al. Excessive incidence of stroke in Iran: Evidence from the Mashhad Stroke Incidence Study (MSIS), a population-based study of stroke 
in the Middle East. Stroke. 2010; 41(1):e3-10. [DOI:10.1161/ STROKEAHA.109.559708] [PMID]

[18] Ayromlou H, Soleimanpour H, Farhoudi M, Taheraghdam AA, Sadeghi Hokmabadi E, Rajaei Ghafouri R, et al. Eligibility assessment for intravenous thrombolytic therapy in acute ischemic stroke patients; evaluating barriers for implementation. Iran Red Crescent Med J. 2014; 16(5):e11284. [DOI:10.5812/ircmj.11284] [PMID] [PMCID]

[19] Aboutalebi Sh, Moghadasian M, Moradi A, Pazoki R. The knowledge assessment of stroke in over age 25 years old habitants of Bushehr port 2005. Iran South Med J. 2006; 9(1):59-65. [In Persian] http:/ / ismj.bpums.ac.ir/article-1-47-en.html

[20] Mojdehipanah H, Yazdi Z, Sayyad Nasiri M, Azizlo Z. Barriers to delivery of tissue plasminogen activator for patients with acute ischemic stroke. Feyz. 2015; 19(2):169-76. [In Persian] http:/ / feyz.kaums.ac.ir/article-1-2625-en.html

[21] American Heart Association. Target: Stroke - When seconds count [Internet]. 2010 [Updated 2010]. Available from: https://www.heart.org/en/professional/quality-improvement/target-stroke/learn-more-about-target-stroke

[22] Dhaliwal J, Ferrigno B, Abiola O, Moskalik A, Sposito J, Wolansky LJ, et al. Hospital-based intervention to reduce tPA administration time. Interdiscip Neurosurg. 2019; 15:15-8. [DOI:10.1016/j.inat.2018.09.005] 
This Page Intentionally Left Blank 